\title{
A rapidly acquired avoidance response in rats
}

\author{
PHARMACEUTICALS RESEARCH DIVISION, E. I. DU PONT DE NEMOURS AND COMPANY
}

A technique is described whereby rats acquired a one-way avoidance response within four training trials and less than 1 min. of total training time. Ninety-eight percent of 500 animals met an avoidance learning criterion and less than $1 \%$ of the animals failed to avoid shock in subsequent repeated tests of avoidance performance.

Rats generally learn a shuttle shock-avoidance response slowly (Baum, 1965) and a fair proportion of the animals (25-40\%) fail to learn at all (Bindra, 1961). Oneway shock-avoidance procedures are somewhat more efficient (Theios \& Dunaway, 1964) but the number of trials required for acquisition and the number of animals rejected as learning failures are still rather high. The present report describes a procedure whereby practically all rats rapidly acquired a reliable one-way shock-avoidance response within four training trials. Method

Subjects. Carworth Farm male rats (CFE) weighing 60-85 gm were used. Food (Wayne Lab-Blox) and water were continually available to them in their 7 in. $x$ 10 in. $x 7$ in. wire-mesh home cages. The animals were housed two or three to a cage. Room temperature was $76^{\circ} \pm 2^{\circ} \mathrm{F}$ and the relative humidity ranged from 45 to $55 \%$.

Apparatus and Avoidance Training. The apparatus was a Lehigh Valley Test Chamber (12 in. x 9-1/2 in. x 10-1/2 in. high) divided into two compartments of unequal size by a partition which contained a 3 in. $x 3$ in. opening. The smaller compartment was $4-1 / 2$ in. long and had a grid floor of 1/4-in. stainless steel rods spaced 1/2 in. apart. The larger compartment was $7-1 / 2$ in. long and had a solid roughened floor raised 1 in. above the level of the grid floor. The walls, ceiling and entrance door to the larger compartment and the lower $3 / 4$ of the entrance door to the smaller compartment were covered with black paper. A loudspeaker was located outside and to the rear of the larger chamber.

Fifteen min. prior to initial training, the fluorescent room lights were turned off and the $14 \mathrm{ft} . \mathrm{x} 20 \mathrm{ft}$. laboratory area was illuminated by a single 15 watt incandescent ceiling bulb. Five hundred rats were trained by giving each of them four successive trials spaced $10 \mathrm{~min}$. apart in which an overhead light (10 watts), a white noise (from a 901 B Grason-Stadler Generator) of $68 \mathrm{db} \pm 1 \mathrm{db}$ (as recorded on the $20 \mathrm{KC}$ weighting scale of a General Radio Corporation Type 1551-C Sound-Level Meter), and a continual scrambled electric shock (0.8 mA, from a Lehigh Valley constant current shock power supply) were presented simultaneously within 1 sec. of placing the animal in the smaller chamber with its head facing the partition opening. If the animal responded (i.e., passed from the smaller to the larger chamber so that all four paws were inside the larger chamber) within a 10-sec.interval timed from the onset of light, noise and shock, the stimulus complex was terminated and the animal was removed from the chamber and returned to its home cage. If the animal failed to respond during the $10-\mathrm{sec}$. interval, the stimulus complex was automatically terminated and the animal was removed from the smaller chamber and returned to its home cage. This technique of presenting light and sound (CS) simultaneously with the shock (US) differs from conventional avoidance conditioning methods in which the CS precedes the US by a certain time interval (Goldstein, 1962). Following the four CS + US trials, each animal was given either one or two "avoidance learning criterion" trials spaced 10 min. apart in which the $C S$ alone was presented within 1 sec. of placing the animal in the smaller chamber and $10 \mathrm{sec}$. prior to US onset. At this point, the animal could (1) avoid shock (i.e., respond during the 10-sec. CS alone interval), (2) escape from shock (i.e., fail to respond to the CS alone but respond during the 10-sec. CS + US interval), or (3) fail to escape from shock (i.e., fail to respond to the CS alone or to the CS + US). The CS was terminated immediately following an avoidance response. The CS + US was terminated immediately following an escape response or automatically terminated if the animal failed to escape. The animal was removed from the chamber immediately following an avoidance or an escape response, or an escape response failure and returned to its home cage. Animals which avoided on one of the two avoidance learning criterion trials were then each given single avoidance trials, $1 / 2,1,2,4,6$, and $24 \mathrm{hr}$. later. Those which failed to avoid on one of the two criterion trials were discarded.

In separate experiments (1) 200 animals were given either one or two (rather than four) CS + US trials followed by one or two avoidance criterion trials under conditions of dim room illumination, (2) 200 animals were given four CS + US trials followed by one or two criterion trials under conditions of normal room illumination, and (3) 200 animals were given four "conventional" training trials in which the CS preceded the US by 10 sec., followed by one or two criterion trials under conditions of dim room illumination.

Since there was a possibility that the CS was inherently aversive to the rats, 20 animals were exposed to four CS-alone trials spaced $10 \mathrm{~min}$. apart, followed by single CS-alone trials $1 / 2,1,2,4,6$, and $24 \mathrm{hr}$. later. A response during the $10-\mathrm{sec}$. CS alone period terminated the CS, but failure to respond did not result in shock. The 
effect of initial exposure to electric shock alone on subsequent avoidance responding to the CS-alone was evaluated by exposing 20 animals to four shock-alone trials (no CS present) spaced $10 \mathrm{~min}$. apart, followed by single CS-alone trials (with no shock for failure to respond) $1 / 2,1,2,4,6$, and $24 \mathrm{hr}$. later. Each animal was removed from the chamber immediately following an avoidance response or avoidance failure and returned to its home cage.

\section{Results and Discussion}

Each of the 500 rats exposed to the four-trial CS + US procedure under conditions of dim room illumination learned to escape from the CS-US complex within the first two CS + US presentations and only 10 of the animals failed to avoid on both avoidance learning criterion trials. Of the 490 animals which therefore met the avoidance criterion only five failed to avoid shock on any of the subsequent single avoidance trials which were given $1 / 2,1,2,4,6$, and $24 \mathrm{hr}$. later. Unlike the rats given four CS + UStrials, only 27 of the 100 animals which received one CS + US trial and 53 of the 100 animals which received two CS + US trials met the avoidance learning criterion, which suggests a steep gradient for avoidance acquisition. Room lighting appeared to be an important factor in avoidance acquisition since only 156 of the 200 animals $(78 \%)$ given four CS + US trials under conditions of normal room illumination met the avoidance learning criterion.

The mean percentage of animals which avoided on the CS-alone trials given $1 / 2$ to $24 \mathrm{hr}$. following initial exposure to four CS-alone trials was $15 \%$ with a range of 5 to $25 \%$. There was no evidence of any trend over trials. Although all of the animals exposed to four shock-alone trials learned to escape from shock within the first two trials, the mean percentage of animals which avoided on the subsequent CS-alone trials given $1 / 2$ to $24 \mathrm{hr}$. later was $20 \%$ (range from 0 to $30 \%$ ) with no evidence of any trend over trials. The results of these two control experiments show that the response to the CS-alone, of the 500 animals which had received four simultaneous pairings of CS and US, was indeed a true avoidance response which derived its strength primarily from the pairing operation and not from the inherently aversive properties of the CS or from non- specific stimulant effects due to prior exposure to electric shock.

Of the 100 animals given four "conventional" CS followed by US tri'ls, $42 \%$ were found to avoid shock on one of the two avoidance criterion trials, which is significantly less (by chi-square test) than the $98 \%$ of animals which avoided shock following four simultaneous CS and US trials. These data indicate that the simultaneous presentation of CS and US results in a more rapid acquisition of avoidance behavior than does the successive presentation of CS and US. The extreme rapidity with which the rats exposed to four simultaneous CS and US trials learned to avoid shock may be related to the strengthening of running behavior in the presence of the CS + US complex with a consequent reduction in the probability of response "freezing"' when the CS was subsequently presented alone. This interpretation is in part supported by the fact that 49 of the 68 animals which failed to avoid on either avoidance criterion trial, after four CS followed by US trials, were observed to "freeze" on one or both criterion trials.

The non-incremental or "all-or-none" nature of avoidance acquisition in the present study is similar to that reported by Theios \& Dunaway (1964) who used a one-way avoidance response motivated by electric shock, and by Ray (1966) who found relatively rapid shuttle-avoidance acquisition when air blast was the US. The present technique, however, appears to generate a more rapid acquisition of shock-avoidance behavior and a considerably smaller rejection rate than has been reported previously.

\section{References}

Baum, M. An automated apparatus for the avoidance training of rats. Psychol. Rep., 1965, 16, 1205-1211.

Bindra, D. Components of general activity and the analysis of behavior. Psychol.. Rev., 1961, 68, 205-215.

Goldstein, Melvin L. Aversive conditioning methodology in animal research. Psychol. Rep., 1962, 11, 841-868.

Ray, J. A., Jr. Shuttle avoidance: Rapid acquisition by rats to a pressurized air unconditioned stimulus. Psychon. Sci., 1966, $5,29-30$.

Theios, J., \& Dunaway, J. E. One-way versus shuttle avoidance conditioning. Psychon. Sci., 1964, 1, 251-252. 